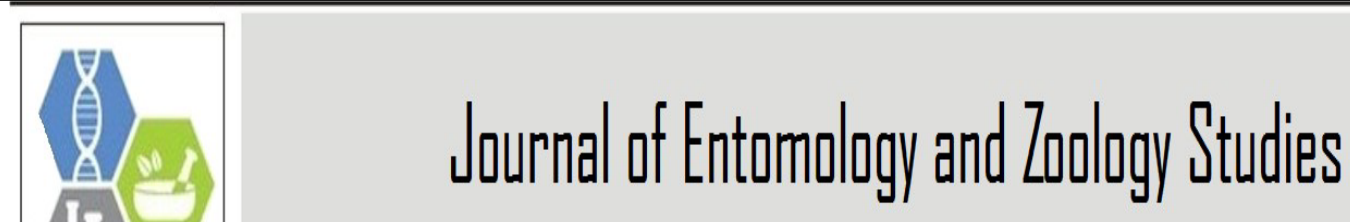

Available online at www.entomoljournal.com

\title{
Sperm storage in Centrobolus inscriptus Attems (Spirobolida: Trigoniulidae)
}

\section{Mark Ian Cooper}

\section{Abstract}

Sperm storage organs and their controlling mechanisms were illustrated for Centrobolus inscriptus. The upper reproductive tract with separate insemination duct, spermatheca and oviduct was sectioned. Muscles controlling sperm movement towards the spermatheca were illustrated and identified as muscles of the bursa and gutter apodematique. Sensory apparatus connected to the spermathecae were illustrated.

Keywords: Centrobolus, Diplopod, millipede

\section{Introduction}

Female morphology in Centrobolus was described ${ }^{[1]}$. The stage II sperm storage with a single spermatheca was shown to constrain last male sperm priorities ${ }^{[2]}$. It has been accepted that (1) the actual site of sperm storage is inaccessible to direct sperm removal, (2) a single sperm store indicates female control by variation in the timing of insemination and re-mating interval, (3) the bursa is distendable and its shape has little bearing on sperm precedence. Muscles with sensory innovations are proposed to control the spermathecae causing sperm to be drawn in when they contract and expelled when they relax. Here I provide illustrative evidence of a stage II sperm storage organ.

\section{Materials and Methods}

The females of Centrobolus inscriptus (Attems 1928) were sacrificed in ethyl acetate jars within $24 \mathrm{~h}$ of mating with conspecific male(s) (1996-1998). The anterior regions of their reproductive tracts were removed by cutting away the integument between the second and third diplo-segments and pinching the junction between the oviduct and the bursa copulatrix. Dissections were immediately placed onto glass slides and viewed with a Wild M400 light microscope. Additional specimens were stored in $70 \%$ ethanol $(\mathrm{EtOH})$ before histological sectioning. On removal from $\mathrm{EtOH}$, a single specimen of each specimen was selected based on the quality of the dissection. The bursa copulatrix was embedded in paraffin wax (melting point $\left.56-60{ }^{\circ} \mathrm{C}\right)$. Sections (1-3 $\mu \mathrm{m}$ thick) were cut on a rocking microtome, stained in haematoxylin/eosin and mounted on glass slides in DPX ${ }^{[3]}$. Additional vulvae were removed from EtOH, dehydrated and prepared for Scanning Electron Microscopy (SEM). SEM micrographs were produced on Cambridge S200 and Leica 440 scanning electron microscopes.

\section{Results}

The sperm storage organ is at stage II of sperm storage organ evolution as insemination duct, spermatheca and oviduct appear to be separate (Figures 1-4).

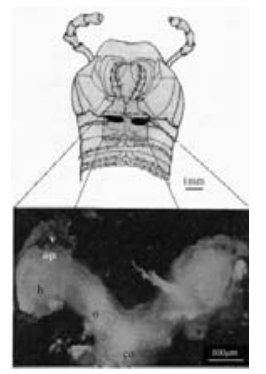

Fig 1: Ventral view of the anterior region of millipede Centrobolus inscriptus showing the female (above) with the upper reproductive tract dissected out to show the vulva (v), bursa copulatrix (be), oviduct (o), common oviduct (co) and operculum (op).

$$
\sim 392 \sim
$$




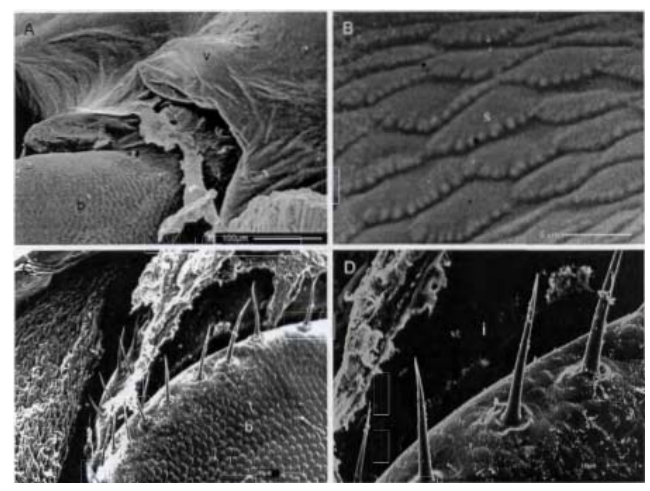

Fig 2: Female reproductive tract of the spirobolidan millipede Centrobolus inscriptus. A. Folds of distendable vulva tissue (v) that ca $\mathrm{n}$ be stretched by male appendages during copulation; B. The surface of the bursa comprises overlayed scale cells (s); C. The bursa copulatrix (b) with hairs running alongside the opening between two chitinous plates, D. The inward orientation of the hairs when the furrow or insemination duct (i) is accessible.
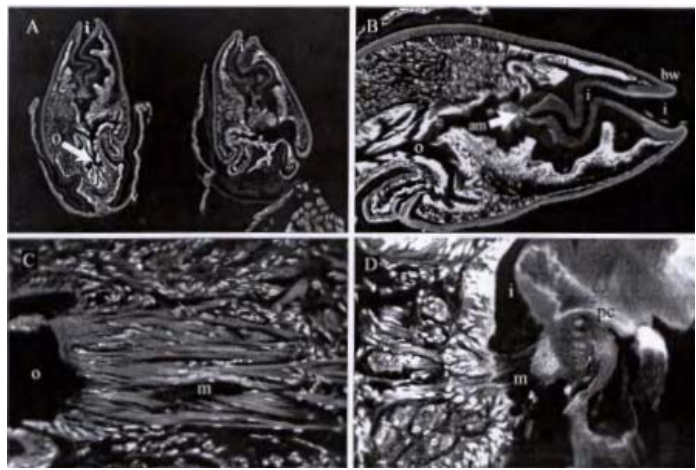

Fig 3: Cross sections through the bursa copulatrix of the spirobolidan millipede Centrobolus inscriptus. A. Left and right bursae showing the insemination duct or furrow (i) and the oviduct (o) (40X); B. The bursa has two plates with chitinous walls (bw). The insemination duct leads down to the duct of the spermatheca ampulla (am) (100X); C. Muscle tissue (m) connecting the oviduct with the bursa wall (400X); D. Muscle tissue running across the in semination duct and connecting a "pin cushion" (pc) (250X).

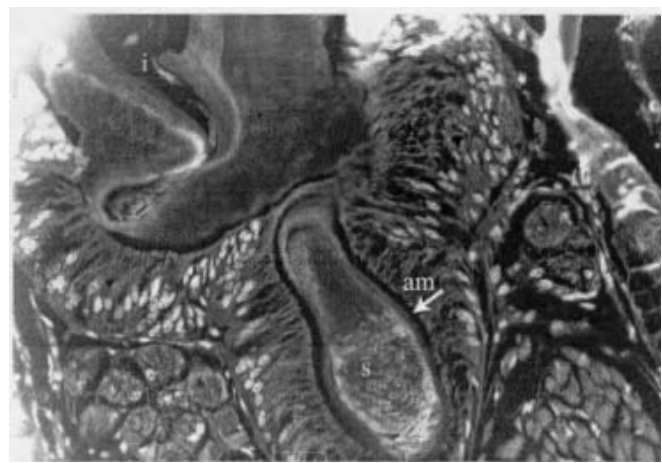

Fig 4: Cross section through the bursa copulatrix of the spirobolidan millipede Centrobolus inscriptus showing that the insemination duct is separate from the spermathecal ampulla (am) where the sperm (s) are stored.

\section{Discussion}

The distendable properties of the vulva membranes allow the male genitalia to penetrate and contact the insemination site during copulation. This is probably realised in all juliform millipedes with indirect sperm transfer by the gonopods (progoneate mating). The implications of the finding that the sperm storage organ is at stage II of sperm storage organ evolution with insemination duct, spermatheca and oviduct are separate are given by Eberhard (1996) ${ }^{[4]}$; males can only access the bursa and insemination duct which are temporary sperm stores. Sperm displaced from the temporary sperm may affect displacement from the bursa by a flushing strategy or flooding the oviduct with sperm ${ }^{[4]}$. This indicates female control over variation in sperm volumes retained and affected by the timing of insemination and re-mating ${ }^{[2,5]}$. The sperm storage organ is distendable and its shape may have no bearing on sperm precedence. Muscles with sensory innovations are proposed to control the spermathecae causing sperm to be drawn in when they contract and expelled when they relax, resulting in dumping or storage.

\section{References}

1. Cooper MI. Sperm storage in Centrobolus spp. and observational evidence for egg simulation. Journal of Entomology and Zoology Studies. 2016; 4(1):127-129.

2. Cooper MI. Competition affected by re-mating interval in a myriapod. Journal of Entomology and Zoology Studies. 2015; 3(4):77-78.

3. Humanson GL. Animal tissue techniques. W. H. Freeman \& Company, San Francisco, 1962, 458.

4. Eberhard WG. Female Control: Sexual Selection by Cryptic Female Choice. Princeton University Press, Princeton, 1996, 501.

5. Barnett M, Telford SR. The timing of insemination and its implications for sperm competition in a millipede with prolonged copulation. Animal Behaviour. 1994; 48:482-484. 